\title{
Statistical and Experimental Study of the Stretching Force for 6061 Aluminum Alloy Using post stretching and pre strecting processes
}

\author{
Sadiq Jaffar Aziz \\ Mohammed Dahkil Abbas \\ Mechanical Engineering department, University of technology, Baghdad, Iraq \\ s-j-aziz@hotmail.com mh_da_ab@yahoo.com
}

\begin{tabular}{|l|l|l|}
\hline Submission date:- 13/3/2019 & Acceptance date:- 7/4/2019 & Publication date:-8/5/2019 \\
\hline
\end{tabular}

\begin{abstract}
An experiment and a statistic study was performed considering the effect of two important input parameters (stretching force and stretching speed) on the stretching behaviour of 6061-0 aluminum sheet in terms of thickness reduction ratio in two types of stretch forming process (post stretching and pre stretching). Experimental tests were carried out using a die with $\mathrm{V}$-shape to stretch the sheet at two selected levels of stretching force and stretching speed and according to the design matrices established by the Design of Experiment (DOE) software (Version 10). Two models with two variable parameters, i.e. stretching force and speed were built by using the response surface methodology (RSM) technique for the two cases of stretching (post and pre stretching), then checked statistically for adequacy purpose by analysis of variance (ANOVA) analysis, and appeared good with $95 \%$ confidence level. It was found that using the post stretch forming process generally gives a lower thickness reduction ratio than that for pre stretching process. This explains the advantages of using post-stretching process to stretch the 6061-0 aluminum sheet alloy.
\end{abstract}

Keyword: Post stretching, Pre strecting, Design of Experiment (DOE), Analysis of variance (ANOVA)

\section{Introduction}

Forming is the process of converting the geometry to the required shape. In this process, a given material is transformed into a useful part having a complex geometry. The stretch forming process was developed as a strategy of putting metals under combined bending and axial tensile stresses at the same time. Sometimes, a part that has been previously bent may be used as an initial material in stretch draw forming. In stretch forming, the sheet is clamped around its edges and stretched over a die or form block. This process strains the metal beyond the elastic limit to set the workpiece shape permanently. Workpieces may have single or double curvatures, as in aircraft skin panels and structure frames, or automobile body parts [1].

In this work, the form block method is used. The form block method is shown in Figure.1. Each end of the blank is securely held in tension by an adjustable gripper, which is moved to stretch the blank over a form block. The final shape of the workpiece is formed by the action of the form block as the metal is moved hydraulically towards the block. [2]

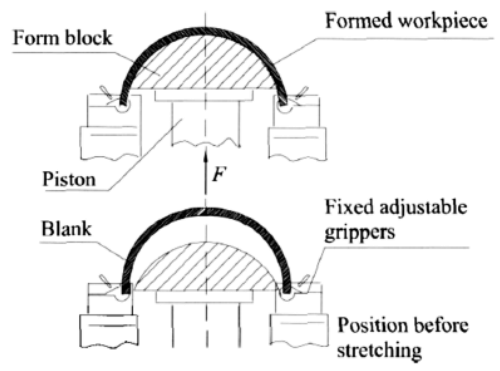

Figure (1): Stretch draw forming with a form block. [3] 
Byoung B. Yoon, et al. [4], presented an experimentally and statistical study of the stress-strain curve of axisymmetric sheet stretching, and measured the overall coefficient of friction along the punch-sheet interface. They Predicted values of loads, deflections, strain distributions and other relevant data were favorably compared with experimental values of these same quantities.

HE De-hua, et al. [5], proposed a combined method to perform a multi-stage stretch forming process using the strain distribution procedure and the FE to obtain the minimum number of stages and deformation quantity of each stage of large aircraft body parts.

Omar S. Es-Said, et al. [6], examined sheets of aluminum-lithium alloy (2195). The rolling direction was considered as a ruling factor for the stretching tests. Three testing sets were examined in different orientation angles $\left(0^{\circ}, 45^{\circ}\right.$ and $90^{\circ}$ angle with respect to the original rolling direction) and stretching condition with different heat treatments.

Heli Peng., et al. [7], studied a numerical simulation using finite element method (FEM) of flexible multi-gripper stretch forming machine used for double-curvature metal sheet forming. They used stress, strain, thickness and springback values of spherical parts for two kinds of drawing modes

Zhu Caichao and Luo Jiayuan, [8], achieved a numerical simulation and experimental test in order to obtained stress variation curves and residual stress in different stretch rates for pre stretching process of the (7075) aluminum alloy sheet,

Venkatachalam G., et al. [9], presented the formability fundamental measured by Forming Limit Diagram (FLD) of sheet metal of aluminum alloy (1050A) which was subjected to cold working process. The limiting or failure strains in sheet metal forming were represented by Forming Limit Curve (FLC).

Reza Esmaeilizadeh, et al. [10], obtained a comparison using commercial sheet of aluminum alloy (1200) stretch forming between simulation and experimental test. Finite element analysis of the forming process was carried out using ABAQUS/Explicit by considering Von Mises and Hill-1948 yield criteria. The

Jawhar El Gueder, et al. [11], studied the cold stretch forming process on a thin plate of aluminum alloy 5154 which was widely used in car manufacturing. The study depended on numerical tool (ABAQUS) to predict the behaviour of the sheets during the stretching process and to estimate mechanical characteristics in the formed shapes.

According to the previous research works, it can be noted that some researches works have experimentally concentrated on the stretch forming fundamentals and principals by establishing the forming limit diagram (FLD) and forming limit curve (FLC) at different stretch forming conditions. Also, most of these researches have mainly concentrated on the numerical simulation by FEM models combined with experimental tests to predict the behavior of the used sheets during the stretch forming process. Consequently, it can be said that there is a little research work regarding modeling and optimization of stretch forming process parameters by using DOE tool with RSM technique and analysis of variance (ANOVA). Thus, the aim of the present work is to build mathematical models relating the response with the input factors to predict the influence of stretching force and speed on the thickness reduction ratio of the stretched aluminum sheet in both post and pre stretching processes and then to determine their optimum values for the selected used levels. Additionally, confirmation tests will be conducted for comparison purpose between the experimental and predicted results.

\section{Experimental works}

\section{Preparing and Testing the Used Material}

Aluminum alloy with a code name (6061-0) and $1.62 \mathrm{~mm}$ thickness was used as a test specimen. Choosing this material is related to the manufacturing process of airplanes body skin parts [3] and many other applications. The chemical composition done by the national center of quality control of the used material is shown in table (1). 
Table 1: Chemical composition of aluminum (6061-0).

\begin{tabular}{|c|c|c||}
\hline Element & Standard (wt. \%) & Used Material (wt. \%) \\
\hline \hline $\mathrm{Al}$ & $95.8-98.6$ & 97.7 \\
\hline $\mathrm{Cr}$ & $0.04-0.35$ & 0.185 \\
\hline $\mathrm{Cu}$ & $0.15-0.4$ & 0.224 \\
\hline $\mathrm{Fe}$ & $\mathrm{Max} 0.7$ & 0.37 \\
\hline $\mathrm{Mg}$ & $0.8-1.2$ & 0.81 \\
\hline $\mathrm{Mn}$ & $\mathrm{Max} 0.15$ & 0.1 \\
\hline $\mathrm{Si}$ & $0.4-0.8$ & 0.435 \\
\hline $\mathrm{Ti}$ & $\operatorname{Max} 0.15$ & 0.15 \\
\hline $\mathrm{Zn}$ & $\operatorname{Max} 0.25$ & 0.026 \\
\hline Other, each & $\operatorname{Max} 0.05$ & 0.0 \\
\hline Other, total & $\operatorname{Max} 0.15$ & 0.0 \\
\hline
\end{tabular}

\section{Test Rig Components}

A complete test rig is manufactured and developed for determining the stretching effect and forming capabilities for the specimen, which incorporates the capability to vary the characteristics of the specimen plate. The designed testing rig as shown in the Figure (2) and Figure.(3), consists of,

a. Main hydraulic pump driven by an electrical motor

b. Secondary hydraulic pump driven by an electrical motor

c. Control board

d. Hydraulic controller

e. Main hydraulic cylinder jack with a maximum capacity of $(56.5 \mathrm{kN})$,

f. A pair of secondary hydraulic cylinder jack with a maximum capacity of $(13.1 \mathrm{kN})$.

g. Gauges, limit switches, pipes and tubes. 


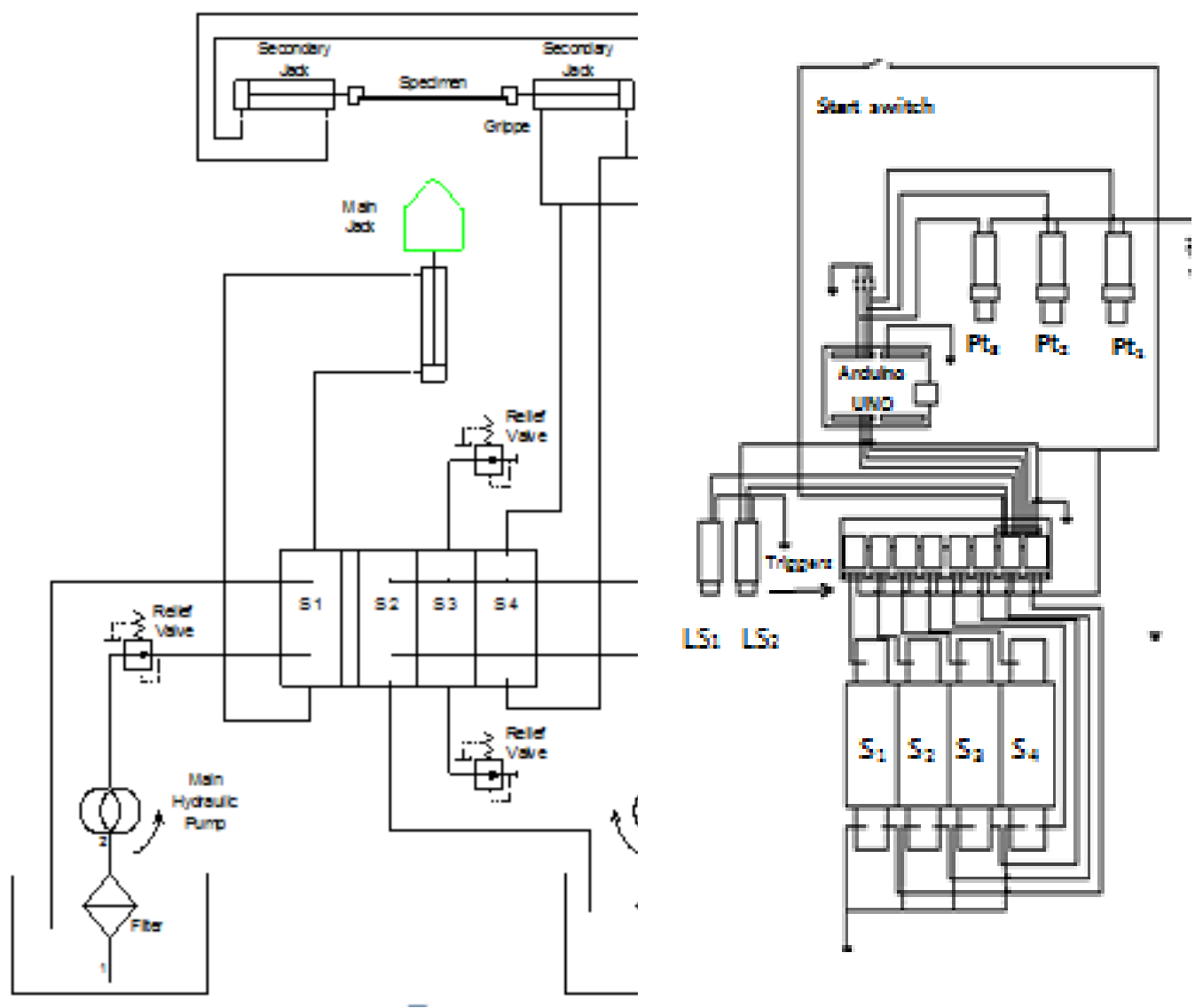

Figure. 2: Hydraulic and electric controller schematic

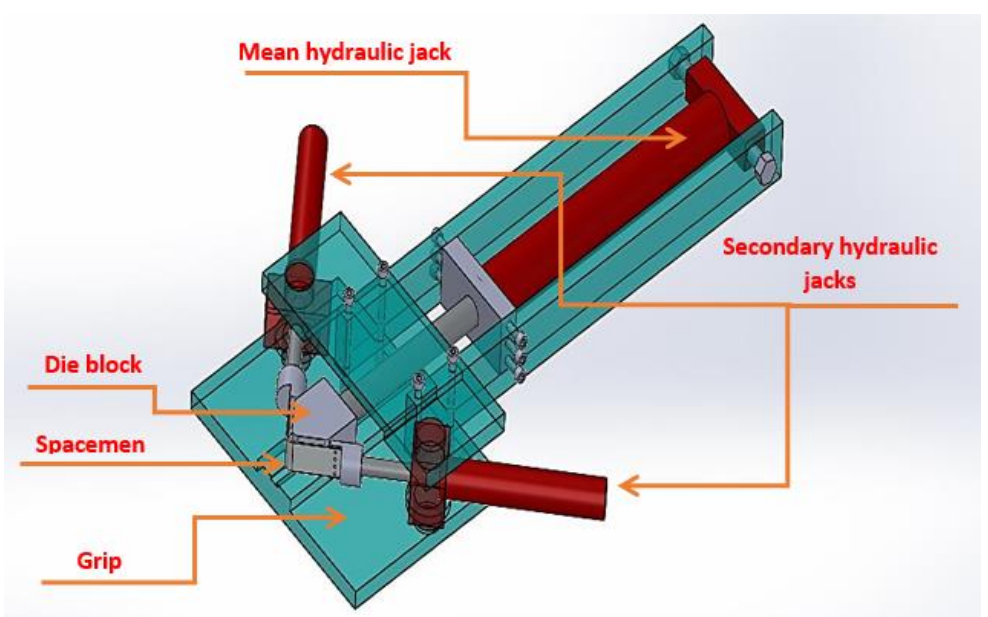

Figure. 3: Test Rig with Preparing $90^{\circ}$ Die with V shape

\section{Specimens preparing}

To produce a typical and correct size of the test specimens, a template made of steel was manufactured as shown in Figure (4), where the pre-cut specimen is fixed between the two parts of the template, and a CNC program is run to perform the edges cutting process resulting typical size specimens, as shown in Figure (5). 


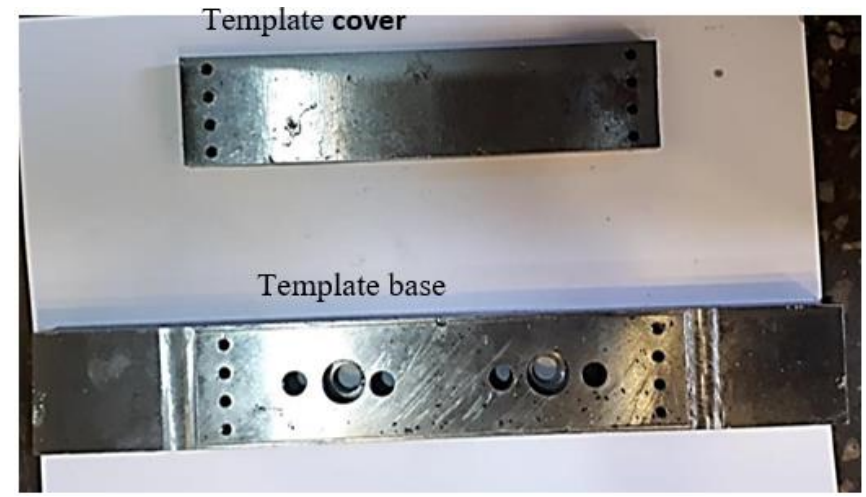

Figure. 4: Cutting Template
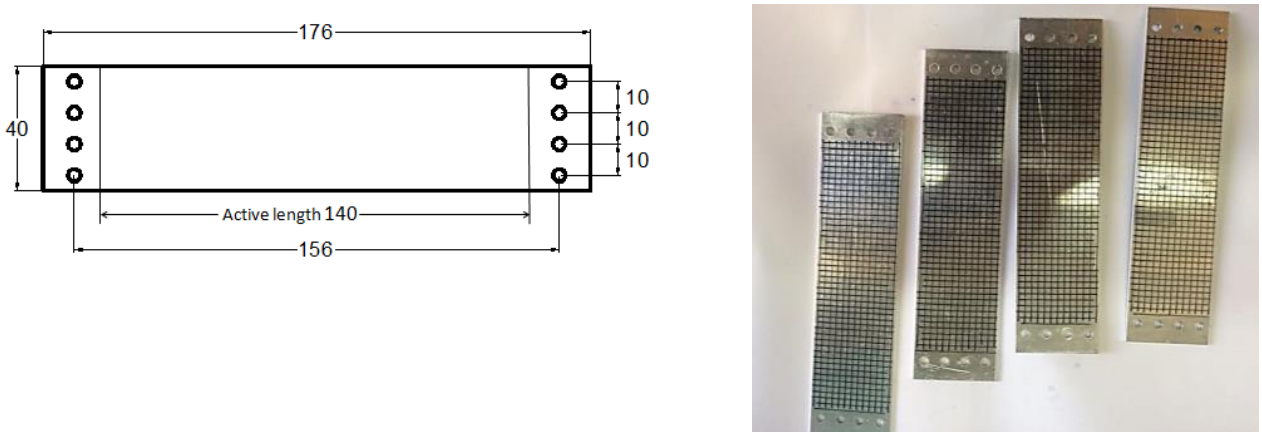

Figure. 5: Specimen drawing (dimensions in $\mathbf{m m}$ ) and Specimen grid

- The first case is to perform the stretching process by initial stretch (pre stretching) for the specimen using the secondary jack to reach a point near to the yielding limit and then the main jack starts to form the specimen till it reaches the final limit for its motion, through its motion the hydraulic controller keeps the forces produced by the jaws constant by controlling the oil pressure. After reaching the final limit, the jaws start to complete the stretching process to approach the required plastic limit. Figureure 6 (A) explains the first case of stretching process.

- The second case is similar to the first case, but started with zero stretching force in the jaws. Figureure 6 (B) explains the second case (post stretching) process.

Although (6061-0) Al alloy exhibits almost 33\% elongation during the standard tensile test (ASTM), which cannot be achieved in stretch forming operation due to the process nature. Any surface defects like knurl on the sheet will early tear the material. So to prevent the occurrence of such early tearing, the sheet edges were deburred.
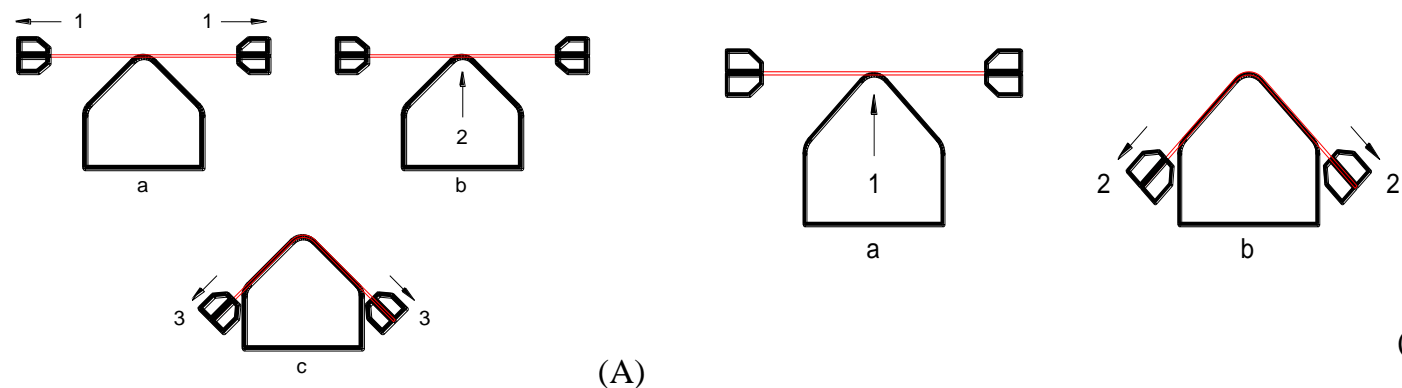

(A)

Figure.6: First stretching case (pre stretching) and Second stretching case post stretching 


\section{Statistical study}

\subsection{Modeling of Thickness Reduction Ratio in post stretching}

The experimental design matrix utilized for the input factors with the experimental measured and average calculated values of thickness reduction ratio in post stretching is given in Table (2). ANOVA analysis of output surface squared model of thickness reduction ratio is carried out for statistical analysis the obtained data, as shown in the Table (3). F-value 48.64 of the model indicates that this model is significant. 'Prob $>$ F' values $<0.0500$ mean the model terms are significant. In this case, A and $A^{2}$ are the significant model terms. Thus, this model points out that the stretching force (A) had a great impact on the thickness reduction ratio, while the stretching speed (B) was not influential. Because the lack of fit is not significant (with P-value > the 0.05), thus this model is good with a $95 \%$ confidence level. Thus, the final predicted model established for the thickness reduction ratio of post stretching case for the aluminum sheet is given as follows:

Thickness reduction ratio $=1.72290-0.70311 \mathrm{~A}+0.11299 \mathrm{~B}+0.10535 \mathrm{~A}^{2}-7.54359 * 10^{-3} \mathrm{~B}^{2} \ldots$ (1)

The diagnostic checking of the model was performed using residual analysis, and the results are shown in Figureures (7) and (8). The normal probability plot is depicted Figure (7). This Figureure manifests that the residuals fall on a straight line indicating that the errors are distributed normally. Figureure (8) reveals the standardized residuals with respect to the predicted values. The residuals do not appear any clear abnormal pattern and are distributed in both negative and positive directions. This indicates that the model is adequate, and there is no reason to think about any violation of the independence or constant variance assumption. Figureure (9) shows the predicted thickness reduction ratio data versus the actual ones for comparison purpose. This Figureure demonstrates that the predicted values of thickness reduction ratio calculated after sheet thickness measurements are near to the actual ones in the experiments, revealing that there is better agreement between the predicted data and experimental ones. Concerning the individual influence of each input factor deviated from the center point of the chosen level; Figureure (10) illustrates the perturbation of thickness reduction ratio in this model. It depicts that the thickness reduction ratio increased largely with increasing the stretching force (A), but it remained almost constant over the stretching speed range (B). This means that the stretching speed has no impact on the thickness reduction ratio of the sheet. This output is also assured by the two-dimensional contour graph and three-dimensional surface graph manifested in the Figureures (11) and (12), respectively in terms of stretching force and stretching speed, exhibiting that the thickness reduction ratio reduced at a higher level of stretching speed and a lower level of stretching force. It can be noted from these Figureures that increasing the stretching force at a higher level of stretching speed leads to an increase in the thickness reduction ratio value, whereas increasing the stretching speed had no effect on the results of thickness reduction ratio. This ratio increase could be attributed to that increasing the stretching speed at lower level of stretching force is due to the increase of the plastic deformation that leads to more strain hardening.

Table 2: Used matrix design for input factors (stretching force and stretching speed) and outputs (thickness reduction ratio) post stretching

\begin{tabular}{|c|c|c|c|c|}
\hline $\begin{array}{c}\text { Std. } \\
\text { No. }\end{array}$ & $\begin{array}{c}\text { Run } \\
\text { No. }\end{array}$ & $\begin{array}{c}\text { Stretching } \\
\text { force } \\
(\mathbf{K N})\end{array}$ & $\begin{array}{c}\text { Stretching } \\
\text { speed } \\
(\mathbf{m m} / \mathbf{s e c})\end{array}$ & $\begin{array}{c}\text { Thickness } \\
\text { reduction } \\
\text { ratio } \\
(\%)\end{array}$ \\
\hline 1 & 13 & 4 & 5 & 0.95 \\
\hline 2 & 3 & 6 & 5 & 1.55 \\
\hline 3 & 5 & 4 & 10 & 1.02 \\
\hline 4 & 4 & 6 & 10 & 1.77 \\
\hline 5 & 10 & 3 & 7.5 & 0.97 \\
\hline 6 & 7 & 7 & 7.5 & 2.4 \\
\hline 7 & 9 & 5 & 2.5 & 1.15 \\
\hline 8 & 11 & 5 & 12.5 & 1.0 \\
\hline 9 & 8 & 5 & 7.5 & 1.28 \\
\hline 10 & 12 & 5 & 7.5 & 1.4 \\
\hline 11 & 1 & 5 & 7.5 & 1.18 \\
\hline 12 & 6 & 5 & 7.5 & 1.16 \\
\hline 13 & 2 & 5 & 7.5 & 1.29 \\
\hline
\end{tabular}


Table 3: ANOVA for the Output Surface Reduced Squared Model for Thickness Reduction Ratio (Post Stretching)

\begin{tabular}{|c|c|c|c|c|c|}
\hline Source & $\begin{array}{l}\text { Sum of } \\
\text { Squares }\end{array}$ & df & $\begin{array}{l}\text { Mean } \\
\text { Square }\end{array}$ & $\begin{array}{l}\text { F } \\
\text { Value }\end{array}$ & $\begin{array}{c}\text { P-value } \\
\text { Prob > F }\end{array}$ \\
\hline Model & 1.88 & 4 & 0.47 & 48.64 & $<0.0001$ significant \\
\hline $\begin{array}{l}\text { A-Stretching } \\
\text { force }\end{array}$ & 1.47 & 1 & 1.47 & 152.83 & $<0.0001$ \\
\hline $\begin{array}{l}\text { B-Stretching } \\
\text { speed }\end{array}$ & $2.083 E-006$ & 1 & $2.083 E-006$ & $\begin{array}{c}2.161 \mathrm{E}- \\
004\end{array}$ & 0.9886 \\
\hline$A^{2}$ & 0.25 & 1 & 0.25 & 26.38 & 0.0009 \\
\hline$B^{2}$ & 0.051 & 1 & 0.051 & 5.28 & 0.0506 \\
\hline Residual & 0.077 & 8 & $9.641 \mathrm{E}-003$ & & \\
\hline Lack of Fit & 0.039 & 4 & $9.869 \mathrm{E}-003$ & 1.05 & 0.4823 not significant \\
\hline Pure Error & 0.038 & 4 & $9.414 \mathrm{E}-003$ & & \\
\hline Cor Total & 1.95 & 12 & & & \\
\hline \multicolumn{2}{|c|}{ Std. Dev. } & 0.098 & & R-Squared & 0.9605 \\
\hline \multicolumn{2}{|c|}{ Mean } & 1.32 & & Adj. R-Squared & 0.9408 \\
\hline \multicolumn{2}{|c|}{ C.V. \% } & 7.45 & & Pred. R-Squared & 0.8140 \\
\hline \multicolumn{2}{|c|}{ PRESS } & 0.36 & & Adeq. Precision & 23.235 \\
\hline
\end{tabular}

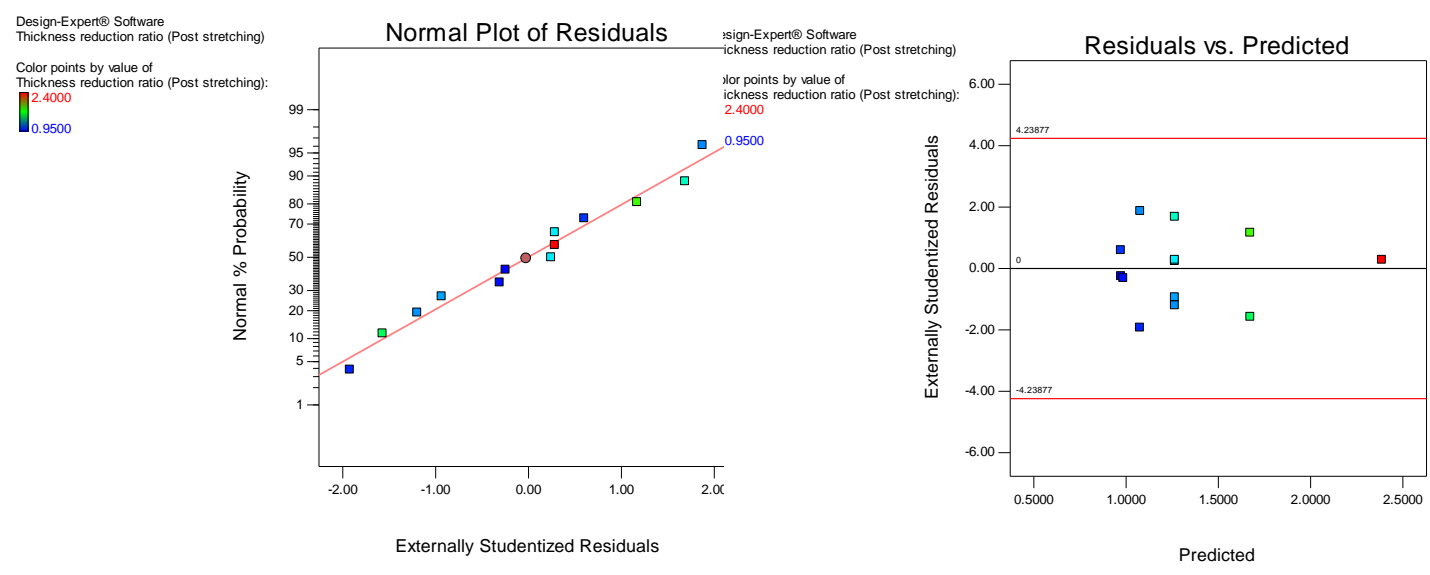

Figure. 7: Normal distribution of thickness reduction ratio data (post stretching)

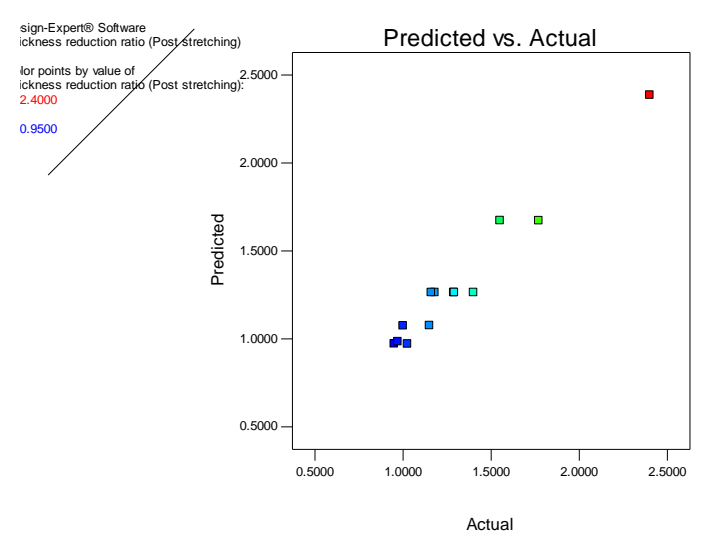

Figure. 9: Predicted vs. actual results (post stretching)
Figure. 8: Residual vs. predicted results (post stretching)

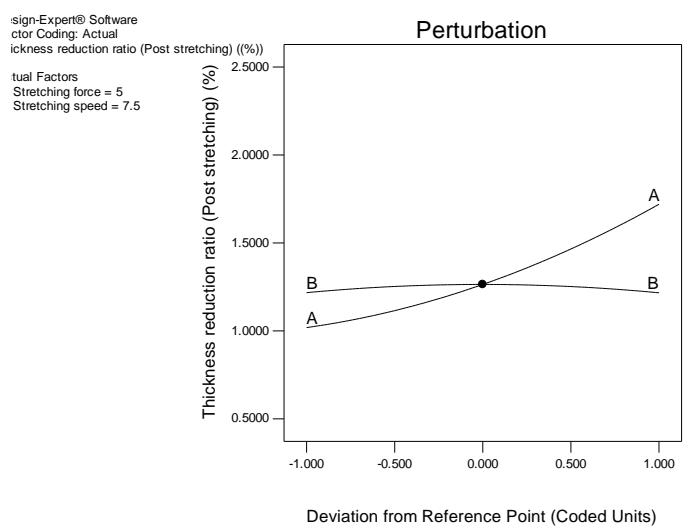

Figure. 10: Perturbation for thickness reduction ratio 


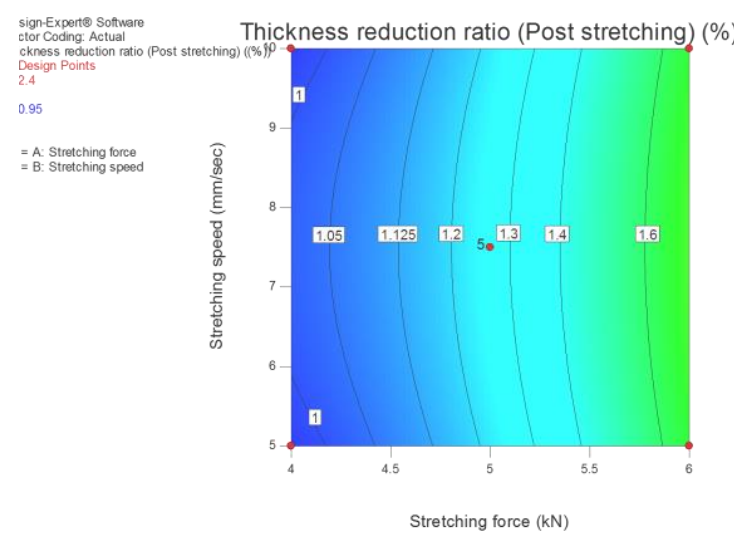

Figure.11: 2D contour plot of thickness reduction ratio as a function of stretching force and stretching speed

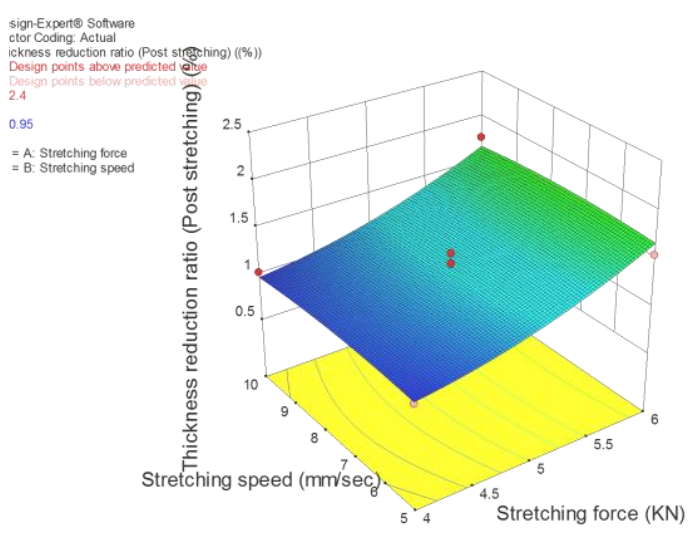

Figure.12: 3D surface plot of thickness reduction ratio as a function of stretching force and stretching speed

\subsection{Modeling of Thickness Reduction Ratio in pre stretching}

The experimental design matrix used for the input factors in terms of actual factors with the experimental average calculated values of thickness reduction ratio in pre stretching is also given in Table 5. ANOVA analysis of output surface squared model of thickness reduction ratio is done for statistical analysis the obtained data, as shown in the Table 5. F-value of 42.00 of the model indicates that this model is significant. 'Prob $>$ F' values $<0.0500$ mean the model terms are significant. In this case, A and B are significant model terms. Thus, this model exhibits that both stretching forces (A) and stretching speed (B) had an effect on the thickness reduction ratio. The determination of coefficient " $\mathrm{R}$ Squared" is a measure of the degree of fit. When "R-Squared" approaches unity, the better-theresponse model fits the actual data. From the same table, the "R-Squared" value for the fit is 0.9546. The "Pred R-Squared" of 0.8752 is in reasonable agreement with the "Adj R-Squared" of 0.9318. Since the lack of fit was not significant (with P-value greater than 0.05), thus the model is good with $95 \%$ confidence level. Therefore, the empirical quadratic built model developed for the thickness reduction ratio in pre stretching of the aluminum alloy sheet is given as follows:

Thickness reduction ratio $($ pre stretching) $=+1.23879+0.80289 \mathrm{~A}-0.44299 \mathrm{~B}+0.076810 \mathrm{AB}-$ $0.076495 \mathrm{~A} 2 \ldots$ (1)

The diagnostic checking of the model was performed using residual analysis. The normal probability plots of the residuals for thickness reduction ratio follows a straight line indicating that the errors (residuals) were normally independently distributed, as shown in Figureure (13). The residuals do not appear any clear abnormal pattern and are distributed in both negative and positive directions; this indicates that the model is adequate, as shown in Figureure (14).

Figureure (13) views the predicted thickness reduction ratio data versus the actual ones. This Figureure reveals that the predicted values of thickness reduction ratio are near to the actual data as obtained in the experiments, exhibiting there is better agreement between the predicted data and experimental ones. Figureure (14) shows the perturbation of thickness reduction ratio and the effect of each input factor during the chosen level. It can be noted that the stretching force appears to increase the thickness reduction ratio at higher level, while the stretching speed decreased this ratio at the higher level, but both of them had the opposite effect on the thickness reduction ratio at lower level. This behavior is confirmed by Figures. (15) and (16) viewing the $2 \mathrm{D}$ and $3 \mathrm{D}$ graphs of the thickness reduction ratio as a function of stretching force and speed. It can be concluded that the stretching force was more effective on thickness reduction ratio than the stretching speed. Also, it can be seen that in this model the thickness reduction ratio decreased to a minimum value due to the combined influence of decreasing the stretching force and increasing the stretching speed at lower level. 
This is more likely ascribed to the increase of work hardening a at higher level of speed during the pre-stretch forming process. The minimum value of thickness reduction ratio at the optimum pre stretch forming input factors will be determined in the statistical optimization section.

Table 5: Used matrix design for input factors (stretching force and stretching speed) and outputs (thickness reduction)

\begin{tabular}{|c|c|c|c|c|}
\hline $\begin{array}{c}\text { Std. } \\
\text { No. }\end{array}$ & $\begin{array}{c}\text { Run } \\
\text { No. }\end{array}$ & $\begin{array}{c}\text { Stretching } \\
\text { force } \\
\text { (KN) }\end{array}$ & $\begin{array}{c}\text { Stretching } \\
\text { speed } \\
(\mathbf{m m} / \mathbf{s e c})\end{array}$ & $\begin{array}{c}\text { Thickness } \\
\text { reduction } \\
\text { ratio } \\
(\%)\end{array}$ \\
\hline 1 & 13 & 4 & 5 & 2.4 \\
\hline 2 & 3 & 6 & 5 & 3.2 \\
\hline 3 & 5 & 4 & 10 & 1.83 \\
\hline 4 & 4 & 6 & 10 & 3.4 \\
\hline 5 & 10 & 3 & 7.5 & 1.4 \\
\hline 6 & 7 & 7 & 7.5 & 3.9 \\
\hline 7 & 9 & 5 & 2.5 & 3.2 \\
\hline 8 & 11 & 5 & 12.5 & 2.5 \\
\hline 9 & 8 & 5 & 7.5 & 3.0 \\
\hline 10 & 12 & 5 & 7.5 & 3.0 \\
\hline 11 & 1 & 5 & 7.5 & 2.7 \\
\hline 12 & 6 & 5 & 7.5 & 3.09 \\
\hline 13 & 2 & 5 & 7.5 & 3.14 \\
\hline
\end{tabular}

Table 6: ANOVA for the Output Surface Reduced Squared Model for Thickness Reduction Ratio

\begin{tabular}{|c|c|c|c|c|c|c|}
\hline Source & $\begin{array}{l}\text { Sum of } \\
\text { Squares }\end{array}$ & df & $\begin{array}{l}\text { Mean } \\
\text { Square }\end{array}$ & $\begin{array}{c}\mathbf{F} \\
\text { Value }\end{array}$ & \multicolumn{2}{|c|}{$\begin{array}{c}\text { P-value } \\
\text { Prob > F }\end{array}$} \\
\hline Model & 5.08 & 4 & 1.27 & 42.00 & \multicolumn{2}{|c|}{$<0.0001$ significant } \\
\hline $\begin{array}{l}\text { A-Stretching } \\
\text { force }\end{array}$ & 4.52 & 1 & 4.52 & 149.69 & \multicolumn{2}{|c|}{$<0.0001$} \\
\hline $\begin{array}{c}\text { B: Stretching } \\
\text { speed }\end{array}$ & 0.26 & 1 & 0.26 & 8.62 & \multicolumn{2}{|c|}{0.0188} \\
\hline AB & 0.15 & 1 & 0.15 & 4.88 & \multicolumn{2}{|c|}{0.0582} \\
\hline$A^{2}$ & 0.15 & 1 & 0.15 & 4.83 & \multicolumn{2}{|c|}{0.0593} \\
\hline Residual & 0.24 & 8 & 0.030 & & \multirow{2}{*}{\multicolumn{2}{|c|}{ not significant }} \\
\hline Lack of Fit & 0.12 & 4 & 0.031 & 1.05 & & \\
\hline Pure Error & 0.12 & 4 & 0.030 & & & \\
\hline Cor Total & 5.32 & 12 & & & & \\
\hline \multicolumn{2}{|c|}{ Std. Dev. } & \multicolumn{2}{|l|}{0.17} & \multicolumn{2}{|c|}{ R-Squared } & 0.9546 \\
\hline \multicolumn{2}{|c|}{ Mean } & \multicolumn{2}{|l|}{2.83} & \multicolumn{2}{|c|}{ Adj. R-Squared } & 0.9318 \\
\hline \multicolumn{2}{|c|}{ C.V. \% } & 6.15 & & \multicolumn{2}{|c|}{ Pred. R-Squared } & 0.8752 \\
\hline \multicolumn{2}{|c|}{ PRESS } & 0.66 & & \multicolumn{3}{|c|}{ Adeq. Precision } \\
\hline
\end{tabular}




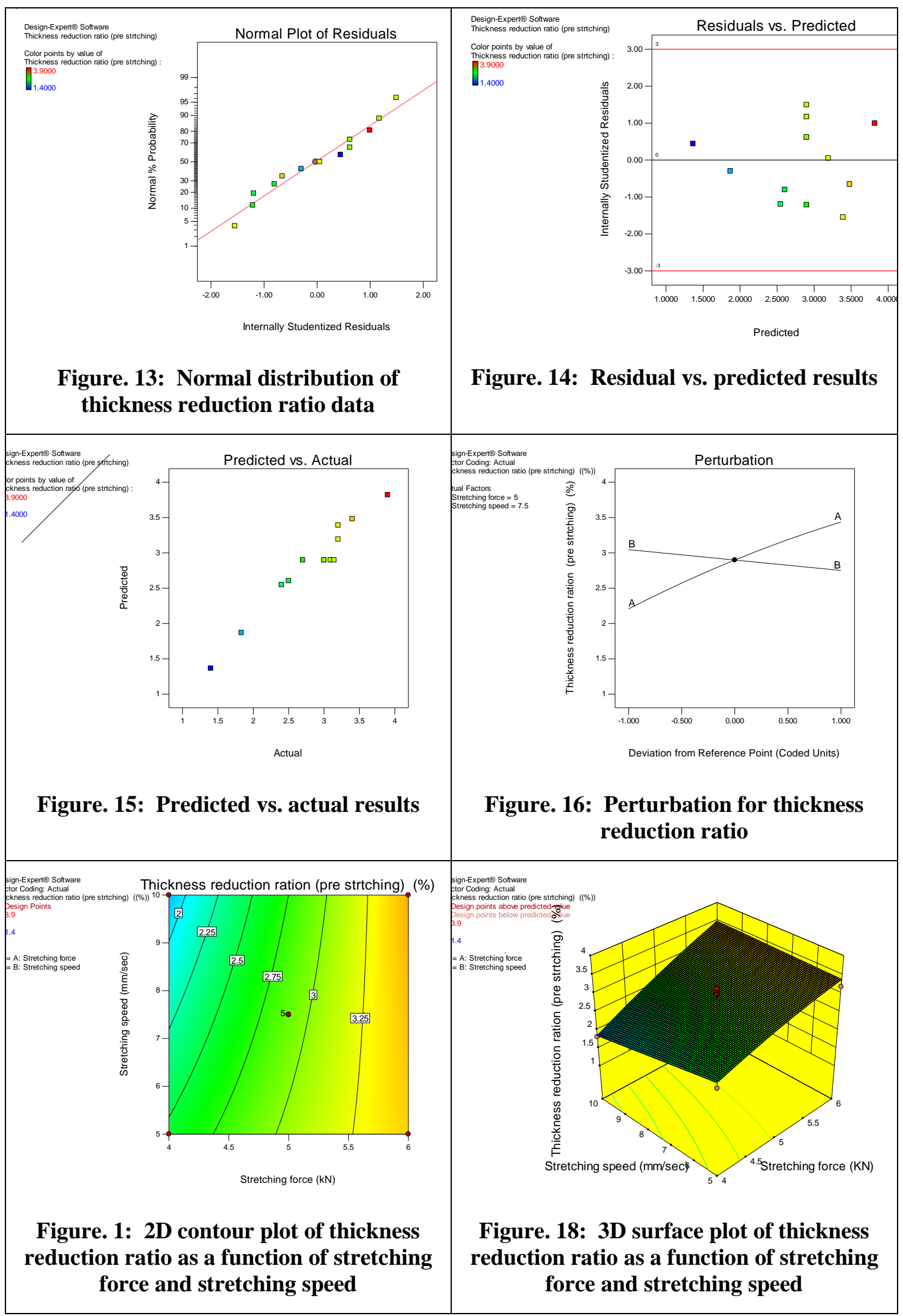




\section{Statistical Optimization of Thickness Reduction Ratio in Post and Pre Stretching}

Statistical optimization was done through a DOE program to determine optimal combination of input factors so as to achieve the required response. Thus, the program is employed to this optimization purpose, depending on the results from the predictive models for response, values of thickness reduction ratio, as a function of two input factors (stretching force and stretching speed) as follows: To build the predicted model, an objective function named "Desirability", which combines properly all goals, is evaluated. The desirability is an objective function, to be maximized by a statistical optimization, which takes a value from zero to one at the goal. The characteristics of a goal might be varied by controlling the importance and weight of desirability, also the purpose of the statistical optimization was to obtain a good conditions set that will fulfil the goals. In the present work, weights were fixed, because the response (thickness reduction ratio) possesses the principal importance. Ultimate goal of this statistical optimization is to obtain the minimum output that simultaneously meets all the changed properties with a maximum desirability. Table (7) shows the variable's constrains for optimization of thickness reduction ratio. In the table, one run (test) meets these constrains to determine the minimum thickness reduction ratio value with a high desirability value, as shown in Table (8). It is seen that for this test, the maximum selected "desirability" is (0.895). Figureures (17) and (18) reveal the optimum values of the minimum thickness reduction ratio in $3 \mathrm{D}$ surface plot for post and pre stretching. According to table (5.5) and these Figureures, it was found that the minimum value of thickness reduction ratio in post and pre stretching is $(0.9716 \%)$ and $(1.8689 \%)$, respectively

Table 7: Constrains of optimization

\begin{tabular}{|c|c|c|c|c|c|c|}
\hline Name & Goal & $\begin{array}{c}\text { Lower } \\
\text { Limit }\end{array}$ & $\begin{array}{c}\text { Upper } \\
\text { Limit }\end{array}$ & $\begin{array}{c}\text { Lower } \\
\text { Weight }\end{array}$ & $\begin{array}{c}\text { Upper } \\
\text { Weight }\end{array}$ & Importance \\
\hline Stretching force (KN) & is in range & 4 & 6 & 1 & 1 & 3 \\
\hline $\begin{array}{c}\text { Stretching speed (mm/sec) } \\
\begin{array}{c}\text { Thickness reduction ratio (Post } \\
\text { stretching) }\end{array}\end{array}$ & minimize & 0.95 & 2.4 & 1 & 1 & 3 \\
\hline $\begin{array}{c}\text { Thickness reduction ratio (pre } \\
\text { stretching) }\end{array}$ & minimize & 1.4 & 3.9 & 1 & 1 & 3 \\
\hline
\end{tabular}

Table 8: The optimum values of input factors and outputs

\begin{tabular}{|c|c|c|c|c|}
\hline $\begin{array}{c}\text { Stretching force } \\
(\mathrm{KN})\end{array}$ & $\begin{array}{c}\text { Stretching } \\
\text { speed } \\
(\mathbf{m m} / \mathbf{s e c})\end{array}$ & $\begin{array}{c}\text { Thickness reduction ratio } \\
\text { (Post stretching)(\%) }\end{array}$ & $\begin{array}{c}\text { Thickness reduction ratio } \\
\text { (pre stretching) (\%) }\end{array}$ & Desirability \\
\hline 4 & 10 & 0.9716 & 1.8689 & 0.895 \\
\hline
\end{tabular}

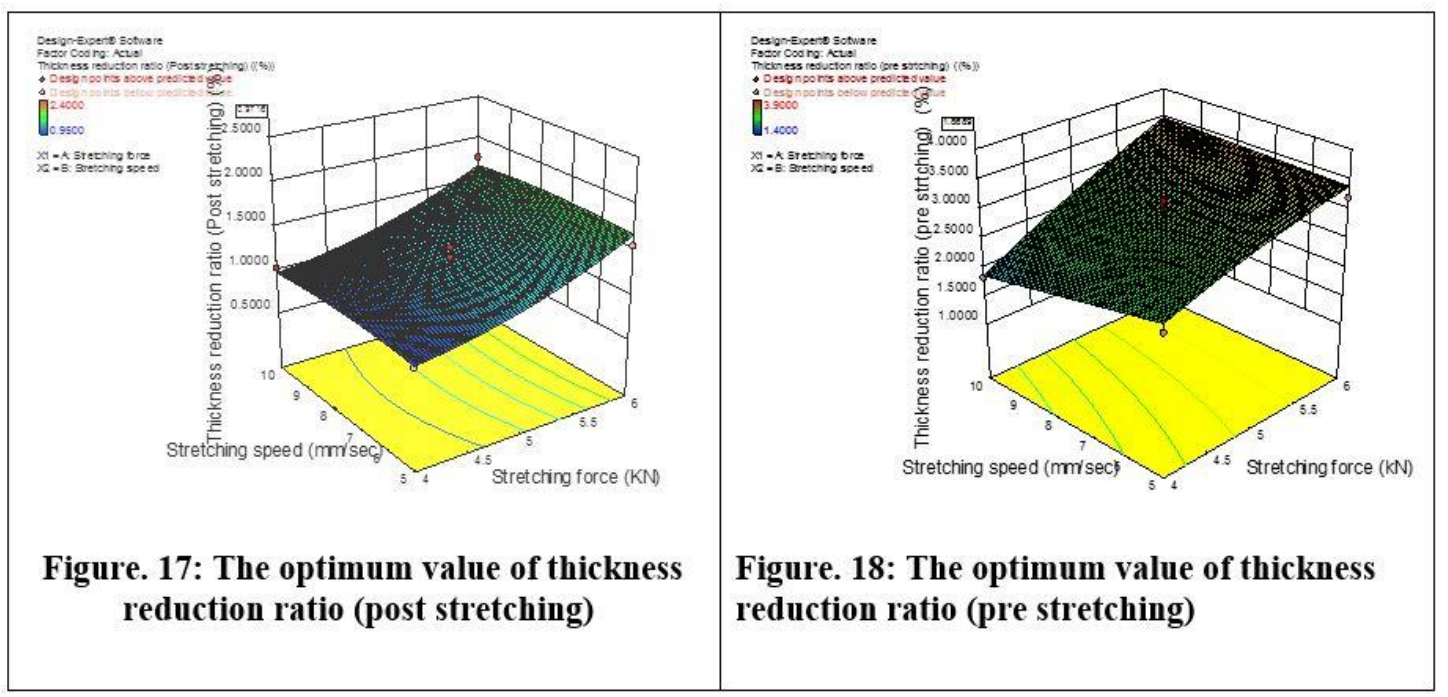




\section{Confirmation tests}

For checking the validity of the predicted models in post and pre stretching, confirmation tests were conducted with the optimum conditions of the input factors determined in these models to obtain the thickness reduction ratio in these two cases (table 7). The experimental data resulted from these tests are listed together with the predicted data in Table (8) to compare between them. This table shows that there is better agreement between the predicted data experimental ones with a maximum error of $5.5 \%$ for post stretching and $1.98 \%$ for pre stretching process

Eventually, for modeling of the thickness reduction ratio for the aluminium sheet, the optimum stretching forming conditions are found to give the minimum reduction ratio within predetermined values. It can be concluded that the optimum values of the conformation test conditions are stretching force of $(4 \mathrm{KN} \mathrm{mm} / \mathrm{min})$ and stretching speed $(10 \mathrm{~mm} / \mathrm{sec})$ with a minimum value of experimental thickness reduction ratio of $(1.0250 \%)$ and $(1.9319 \%)$ for post and pre stretching, respectively, as shown in Table 8

Table 8: Results of confirmation tests at the optimum conditions

\begin{tabular}{|c|c|c|c|c|c|c|c|}
\hline $\begin{array}{l}\text { Stretching } \\
\text { force } \\
\text { (KN) }\end{array}$ & $\begin{array}{c}\text { Stretching } \\
\text { speed } \\
(\mathbf{m m} / \mathbf{s e c})\end{array}$ & $\begin{array}{l}\text { Pred. } \\
\text { thickness } \\
\text { reduction } \\
\text { ratio (post } \\
\text { stretching) } \\
\quad(\%)\end{array}$ & $\begin{array}{c}\text { Exp. } \\
\text { thickness } \\
\text { reduction } \\
\text { ratio (post } \\
\text { stretching) } \\
\quad(\%)\end{array}$ & Error (\%) & $\begin{array}{c}\text { Pred. } \\
\text { thickness } \\
\text { reduction } \\
\text { ratio (pre } \\
\text { stretching) } \\
(\%)\end{array}$ & $\begin{array}{c}\text { Exp. } \\
\text { thickness } \\
\text { reduction } \\
\text { ratio (pre } \\
\text { stretching) } \\
\%\end{array}$ & $\begin{array}{c}\text { Error } \\
(\%)\end{array}$ \\
\hline 4 & 10 & 0.9716 & 1.0250 & 5.50 & 1.8689 & 1.8319 & 1.98 \\
\hline
\end{tabular}

Depending on the table 8, a comparison was performed between the results of the experimental and predicted thickness reduction ratios in both predicted post and pre stretching models. In general, it was found that both experimental and predicted values of thickness reduction ratio in pre stretching are higher than those obtained for post stretching (i.e., $44 \%$ for experimental data and $48 \%$ for the predicted data). These results indicate that the post stretching process is better to be used for (6061-0) aluminium sheet than pre stretching process due to its lower thickness reduction ratio caused by the insignificant effect of stretching speed and the occurrence of more strain hardening effect on the stretched material during this type of stretching.

\section{Conclusions}

a. Quadratic empirical models were developed by using DOE with RSM and ANOVA analysis for post stretching of 6061-0 aluminum sheet over predetermined levels of stretching force and speed.

b. The value of thickness reduction ratio decreased with the decreasing of stretching force, while the stretching speed had insignificant effect at lower and higher used level.

c. The statistical optimization revealed that the minimum value of thickness reduction ratio in post stretching case was $(0.9716 \%)$ at the optimum value of stretching force $(4 \mathrm{KN})$ and stretching speed $(10 \mathrm{~mm} / \mathrm{sec})$.

d. Design of experiment (DOE) with Response surface methodology (RSM) proved to be proper tools for predicting the thickness reduction ratio in stretch forming process for the input parameters used in the present work.

\section{CONFLICT OF INTERESTS.}

- There are no conflicts of interest.

\section{Refrences}

[1] Taylan Altan and A. Erman Tekkay, " Sheet Metal Forming: Fundamentals", ASM International, 2012.

[2] He De-hua, Li Xiao-qiang, Li Dong-sheng and Yang Wei-jun," Process design for multi-stage stretch forming of aluminium alloy aircraft skin", Trans. Nonferorrus Met. Soc. China 20(2010), pp. 1053-1058, Science Direct, 2010.

[3] Vukota Boljanovic," Sheet Metal Forming Processes and Die Design", Industrial Press, 2004.

[4] Byoung B. Yoon, Ravl S. Rao and Nobortj Kikuchi, "Sheet Stretching: a Theoretical-Experimental Comparison", Int. J. Mech. Sci., Vol. 31, No. 8, pp. 579 - 590, 1989. 
[5] He De-hua, Li Xiao-qiang, Li Dong-sheng and Yang Wei-jun," Process design for multi-stage stretch forming of aluminium alloy aircraft skin", Trans. Nonferorrus Met. Soc. China 20(2010), pp. 1053-1058, Science Direct, 2010.

[6] Omar S. Es-Said, C. J. Parrish, C. A. Bradberry, J. Y. Hassoun, R. A. Parish, A. Nash, N. C. Smythe, K. N. Tran، T. Ruperto, E. W. Lee, D. Mitchell, and C. Vinquist, "Effect of Stretch Orientation and Rolling Orientation on the Mechanical Properties of 2195 Al-Cu-Li Alloy", Mechanical Engineering Faculty Works, Loyola Marymount University and Loyola Law School, 2011.

[7] Heli Peng, Mingzhe Li, Qigang Han, Pengxiao Feng and Haohan Zhang," Design of Flexible Multigripper Stretch Forming Machine by FEM", ISSN: 1662-8985, Vols. 328-330, pp. 13-17, Advanced Materials Research, Trans Tech Publications, 2011.

[8] Zhu Caichao and Luo Jiayuan," Stretch rate and deformation for prestretching aluminum alloy sheet", J. Cent. South Univ. (2012) 19, pp 875-881, Springer, 2012.

[9] Venkatachalam G., Veer Kumar and Narayanan S., "Element Analysis of Forming Limits for Stretch Forming of Perforated Aluminum Sheet Metals", ARPN Journal of Engineering and Applied Sciences, Vol. 8, No. 8, August 2013.

[10] Reza Esmaeilizadeh, Kourosh Khalili, Bagher Mohammadsadeghi and Hossein Arabi, "Simulated and experimental investigation of stretch sheet forming of commercial AA1200 aluminum alloy", Trans. Nonferrous Met. Soc. China 24(2014) 484-490, Science Direct, 2014.

[11] Jawhar El Gueder, Eliane Giraud, Nan Zhao and Philippe Dal Santo, "Statistical and Experimental Analysis of Cold Stretching of Aluminum Sheets Using an Instrumented Bench", HAL archives, 2016. 


\title{
در اسة احصائية وعملية لقوة التشكيل بالمط لسبيكة الامنيوم 6061 باستخدام عمليات المط المباشر والمط المسبث الثد
}

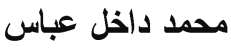 \\ صادق جعفر عزيز \\ قسم الهندسة الميكانيكبة، كلية الهندسة، الجامعة التكنولوجية، بغد/د، العر/ق \\ mhda
}

الخلاصة

تم انجاز دراسة عملية و عددية اخذة بالاعتبار تاثير اثثين من المدخلات المتغيرة المهمة (قوة المط وسرعة المط) على

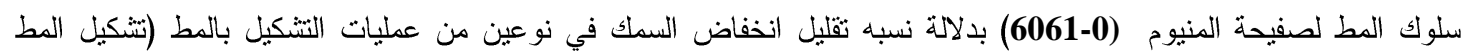
المباثر وتتكيل المط مسبق الثند ) • و اجريت التجارب العملية باستخدام قالب على شكل حرف (V) لمط الصفيحة لمستويين مختارين من قوة المط وسرعة المط وفقا الى المصفوفات التصميمية المنجزة أنثات بواسطة تصميم تجريبي لتقنية (D O E)

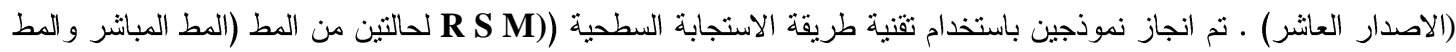

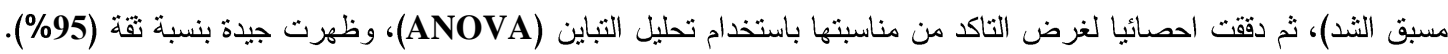

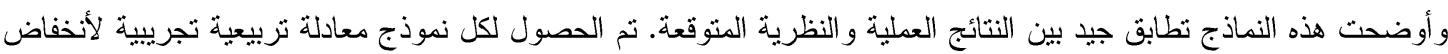
نسبه السمك (كاستجابة) بدلالة قوة المط وسر عة المط (كمعاملات ادخال). بينت نتائج النموذج الاول (تشكيل المط المباشر) اثشارت الى ان قوة المط فقط تمتلك ناثير اعلى من تأثير سرعة المط على نسبه انخفاض السمك والتي وجد ان لها تأثثير ضئيل على هذا

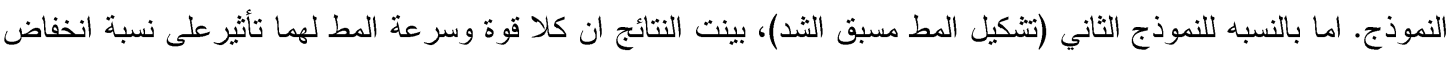

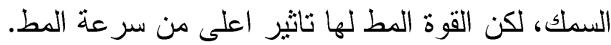
الكلمات الدالة: التتكيل بالمط، تشكيل المط المباشر، تصميم تجريبي لتقنية (D O E)، تحليل التباين (ANOVA). 